\section{Géneros}

Multidisciplinary Journal of Gender: Studies

\section{Hipatia Press \\ www.hipatiapress.com}

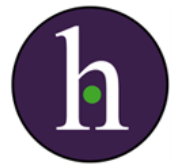

Instructions for authors, subscriptions and further details:

http://generos.hipatiapress.com

\title{
Enunciación de la Violencia de Género y Marco Educativo para su Prevención
}

Rosa San Segundo ${ }^{1}$

Adelina Codina-Canet ${ }^{1}$

1) Instituto Universitario de Estudios de Género, Universidad Carlos III de

Madrid, Spain

Date of publication: February $25^{\text {th }}, 2019$

Edition period: February - June 2019

To cite this article: San Segundo, R., \& Codina-Canet, A. (2019).

Enunciación de la Violencia de Género y Marco Educativo para su Prevención. Multidisciplinary Journal of Gender Studies, 8(1), 26-47. doi: 10.17583/generos.2019.4000

To link this article: http://dx.doi.org/10.17583/generos.2019.4000

\section{PLEASE SCROLL DOWN FOR ARTICLE}

The terms and conditions of use are related to the Open Journal System and to Creative Commons Attribution License (CC-BY). 


\section{Enunciation of Gender Violence and Educational Framework for Prevention}

Rosa San Segundo

Adelina Codina-Canet

University Carlos III of Madrid

\section{Abstract}

This paper deals with gender as a socially constructed category that narrows the conception of gender violence. While violence refers to a way to interact with others, stems from the historical and ancient segregation of women by the fact of being women. This type of violence has its origins in the sexual division of labor and private property. Slavery, which was originally only female, shaped conformed as the most barbaric form of domination. As a result, a symbolic whole world order has been established to legitimize that subordination that is present in every order and exerted through social, cultural, political, psychological, legal, economic constructions and in the audiovisual environment. Gender violence, as a social aggression that is culturally learned, is a strategy to subjugate women that is expressed in many ways: abusive relationships, harassment, etc. Termination and prevention are fundamental measures in gender violence. In this vein, equality and nonviolence are essential for the progress and development of human rights and dignity.

Keywords: gender violence, education, equality, gender perspective 


\section{Enunciación de la Violencia de Género y Marco Educativo para su Prevención}

Rosa San Segundo

Adelina Codina-Canet

Universidad Carlos III de Madrid

\section{Abstract}

Se abordan el género como categoría construida socialmente, para delimitar la concepción de violencia de género. La violencia hace referencia a una forma de interactuar con los otros, procede de la segregación histórica de la mujer que tiene una trayectoria milenaria, se ejerce hacia las mujeres por el hecho de serlo. Tiene sus orígenes con la división sexual del trabajo y la propiedad privada. La esclavitud en un principio fue solo femenina, conformó la violencia de género, ésta ha sido la forma más bárbara de dominación. Como consecuencia, se va a establecer todo un orden simbólico del mundo para legitimar esta subordinación que se va a manifestar en todos los órdenes y se ejerce mediante construcciones sociales, culturales, políticas, psicológicas, jurídicas, económicas, y en el medio audiovisual. La violencia como agresión aprendida social y culturalmente, es una estrategia para someter a las mujeres y se manifiesta de múltiples formas, en relaciones de abuso, de acoso, y otras múltiples las formas que adquiere la violencia de género. La salida y la prevención son fundamentales en violencia de género, así la igualdad y la no violencia son esenciales para el progreso y el desarrollo de los derechos humanos y de una vida en dignidad.

Palabras clave: violencia de género, educación, igualdad, perspectiva de género. 


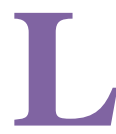

os conceptos género y sexo designan aspectos muy diferenciados. Género no es un concepto dual masculino y femenino y tampoco identifica género a las mujeres. Sexo es un vocablo que alude a cuestiones biológicas físicas, anatómicas, fisiológicas y otras y el vocablo género hace referencia a construcciones sociales, culturales, políticas, psicológicas, jurídicas, económicas y otras. En el presente trabajo se aborda el concepto de género en tanto que categoría construida que instituye un modelo de división sexual del trabajo, un modelo institucional de normas, leyes y una ordenación simbólica de la realidad, con el objeto de subordinar en todos los ámbitos a las mujeres (Beavoir, 2005). Ello va a legitimar una violencia y agresión aprendidas social y culturalmente. Esta violencia contra las mujeres, violencia de tipo sexista, subyace como problema estructural (Pérez del Campo, 1995) y como tal ha de abordarse.

Se presenta una metodología analítica para abordar la construcción del género y de la violencia, escrutando sus formas de proceder y características más esenciales, para tratar de realizar analogías y comprender el fenómeno de la violencia de género de forma que permita establecer criterios fundamentados.

El análisis tradicional realizado desde las diferentes fuentes discursivas que abordan la violencia de género sin tratar una perspectiva multidimencional. Osborne (2001) recopila dos perspectivas desde la instituciones: el planteamiento funcionalista realizado desde instituciones, desde el que no cuestiona el orden social y se limita a describir la violencia en el ámbito familiar, por lo que la considera un problema técnico a resolver por el Estado); y el planteamiento reformista, también elaborado por los poderes públicos y se centra en la prevención.

Los fundamentos teóricos han de complementarse con los conocimientos prácticos de los profesionales que en el contexto de distintas disciplinas están especializados en violencia de género. Sin embargo el discurso transformador emerge de la sociedad civil organizada Movimiento Feminista y las ONGs orientadas a combatir la violencia de género, va más allá en el análisis de la violencia contra las mujeres al tratar de explicar el porqué de la violencia, el cual se considera un problema político. Este último discurso cuestiona la 
capacidad de las instituciones para abordar un problema que no parecen conocer en toda su dimensión (Osborne 2001).

La perspectiva de género permite reinterpretar el germen de la violencia, su reproducción y la actual legitimación. Se pretende contribuir a la reflexión de la violencia contra las mujeres en un análisis estructural de las relaciones de dominación

\section{Contexto de la Violencia de Género}

La violencia, es una forma de interactuar con el otro. Podemos interactuar en relaciones de igualdad, de reciprocidad, de respeto, de convivencia en la pluralidad. $\mathrm{O}$ en las antípodas, podemos establecer relaciones de relaciones de abuso, de acoso, de dominación, estas últimas son las relaciones que se establecen en la violencia. En la violencia, del tipo que fuere, ya sea entre estados, entre grupos diversos o entre personas lo que se persigue es someter la voluntad del otro, de una forma más rápida y eficaz que la tolerancia y el respeto. La violencia es eficaz en tanto es una forma muy rápida de dominación, y es por ello que se emplea. La violencia es un medio para conseguir otras cuestiones como la dominación en principio, la violencia sólo puede encontrarse en el contexto de los medios y no en el de los fines, La violencia en su forma original es pura manifestación, no es medio para sus fines, apenas si puede considerarse manifestación de sus voluntades. Es ante todo manifestación de su existencia (Benjamín, 2001).

Violencia doméstica hace referencia a aquella que se produce dentro del hogar, tanto del marido a su esposa, como del padre a sus hijos, u otras. Este concepto excluye aquellas relaciones de pareja o no en las que no hay convivencia. Es más precisa la terminología de violencia de género, ya que abarca todos los actos mediante los cuales se discrimina, ignora, somete y subordina a las mujeres en los diferentes aspectos de su existencia (Maquieira, V.; Sánchez, C. 1990). Es todo ataque material y simbólico que afecta a la libertad, dignidad, seguridad, intimidad e integridad moral y/o física de las mujeres.

La violencia de género es la violencia que se ejerce hacia las mujeres por el hecho de serlo (Pérez del Campo, 1995), se fundamenta en el sexismo. La concepción segregacionista del sexismo es similar a otras formas de 
segregación como el racismo, el clasismo u otras formas de segregación. Incluye malos tratos a la pareja, agresiones físicas, sexuales, mutilación genital, infanticidios, feminicidios, daño o menoscabo físico, sexual o psicológico para la mujer, inclusive las amenazas de tales actos, la coacción, tanto si se producen en la vida pública o privada y otras muchas formas de violencia. Todos estos actos de violencia basados en la pertenencia al sexo femenino, según el Artículo 1 de la Declaración sobre la Eliminación de la Violencia contra la Mujer de Naciones Unidas de 1994 (Martín Casares 2006).

La violencia de género procede de la segregación histórica de la mujer que se retrotrae a una historia de milenios. Tiene sus orígenes con el establecimiento de la división sexual del trabajo y la propiedad privada (Amorós, 1990). La teoría social de género y sexualidad con perspectiva feminista interpreta el origen de las relaciones desigualitarias de género (Venegas, 2010), marcadas por la opresión y la subordinación de las mujeres.

Lévi-Strauss (1969) ofrece un modelo estructuralista para explicar el origen de la cultura y la incidencia de ésta en las relaciones de dominación. La opresión de las mujeres se encuentra en el origen mismo de la cultura, y conformándose un sistema patriarcal, donde el tabú del incesto instituye los prolegómenos de los derechos de los hombres y de la cultura patriarcal, se reconoce la paternidad biológica y se regulan las relaciones sexuales mediante un sistema de prohibiciones (Sau, 2001), originándose una forma primigenia del control del cuerpo de las mujeres por parte de los hombres. El tabú del incesto, según el antropólogo francés, se puede constatar como el primer acto de cultura

En la historia de la humanidad cuando se produjo el paso del nomadismo al sedentarismo, generado éste en torno a los grandes ríos (Tigris, Éufrates Ganges, Nilo, Yangtzé...) se gestaron los primeros los asentamientos agrícolas, consecuencia de ello se empezaron a acumular los excedentes agrícolas, dándose inició a una organización contable para los mismos, nace así la escritura como necesidad contable (Goodoy, 1990) que va a gestar la propiedad privada (Gerner, 1986). La propiedad privada coadyuva a la invasión de otros pueblos con el objeto de apropiarse de sus nuevas riquezas acumuladas. Este incipiente militarismo va venir acompañado por el origen de la esclavitud femenina, pues en las invasiones y guerras se esclavizaba 


\section{San Segundo \& Codina-Canet-Violencia de Género}

solo a las mujeres, y a varones se les mataba. Solo cuando las esclavas fueron abusadas y tuvieron descendencia se vislumbró la existencia de la personalidad esclava y dio comienzo, también, a la esclavitud masculina. Se esclavizó, en un momento posterior, a los varones hijos de las esclavas (Gerner, 1986). La esclavitud, como concepción, en un principio fue solo femenina, conformó la violencia de género, y esta ha sido la forma más bárbara de dominación (Gerner, 1986).

Vestigios de la antigua esclavitud de las mujeres quedan en nuestra sociedad actual con el derecho de los hombres al cuerpo de las mujere humana (Kubissa, 2015), y al acceso al mercado de cuerpos mediante la prostitución en una sociedad que banaliza, normaliza e invisibiliza la utilización, uso y prostitución de mujeres, una sociedad que legitima las raíces de la desigualdad humana (Miguel, 2015). La dominación de las mujeres estableció la utilización y comercio del cuerpo de éstas (Cobo, 2017).

La segregación de las mujeres vino antecedida y se conformó a través de la violencia (Amorós, 1990), consumándose así su sometimiento Como consecuencia, se va a establecer todo un orden simbólico del mundo para legitimar esta subordinación que se va a manifestar en todos los órdenes necesario para establecer legitimar esta dominación. (Bautista, 2004). Se va a establecer en el lenguaje, en los conocimientos, en las religiones (monoteísmos), en los cuentos infantiles y en otros muchos. Pero la esclavitud, para establecerse y normalizarse sin apariencia de violencia, precisó de la elaboración de un orden simbólico de subordinación. Cimentada tal construcción social del mundo, el dominio sobre las mujeres estaba ya plenamente implantado y aceptado bajo el fundamento inamovible de la normalidad. La desigualdad estaba en el lenguaje, en el pensamiento, en la cultura... el propio género se convirtió en metáfora de las relaciones de poder. Lo femenino dejó de ser simbólicamente poderoso con la emergencia de ritos, creencias, mitos, valores, discursos. El orden que invisibiliza y hasta expulsa a las mujeres del mundo, de la cultura, de los conocimientos, de la ciencia, del lenguaje, de los conceptos, de la espiritualidad, de la creación, de los sueños... arrojó también a las diosas del cielo. Es en ese momento cuando el mundo, lo sagrado, lo interno, lo venerable, dejó de ser femenino. Además, las formas de dominación mutan por lo que hay una gran 
perdurabilidad de este sistema que tiene una longevidad de milenios (Venegas, 2010).

La dominación masculina obedece al establecimiento de un orden arbitrario de las cosas y de las actividades instaurado una oposición masculino y femenino, dicotomía que se establece como diferencia biológica natural, posteriormente se va a producir la asimilación de la dominación, a partir de lo cual se otorga al hombre el poder de dominar a las mujeres y se establece la violencia simbólica, resultado de un proceso largo (Bourdieu, 2000).

\section{Manifestaciones de la Violencia de Género}

La violencia es una agresión aprendida social y culturalmente, es una estrategia para someter a las mujeres, consecuencia de la posición subordinada establecida de las mujeres en la sociedad (Osborne, 2001). El sexismo tiene muchas similitudes en su manifestación social con el racismo, el clasismo y a otras formas de segregación, donde un grupo se siente y actúa con superioridad en todo y en derechos sobre otro grupo. Todo ello se percibe con normalidad y cierta tolerancia e invisibilidad social (Osborne, 2001). La violencia de género no es el producto de unas mentes enfermas, de hombres traumatizados o de una pelea pasional, realizada de forma aislada e individualizada. Sino que se fundamenta en la idea de que hay seres que se sienten superiores que tienen derecho al poder sobre los otros, en este caso los hombres sobre las mujeres.

La violencia no es una cuestión genética sino es aprendida. Se aprende en los primeros meses de vida. En la infancia, si se vive un ambiente de relaciones de violencia se aprende este modelo de relacionarse con los demás, las semillas de la violencia se plantan en los primeros años de vida en el seno del hogar se cultivan en un medio social impregnado de desigualdades y frustraciones (Rojas Marcos, 1995). Si la infancia no se ha transitado en un ambiente de violencia o de relaciones de abuso es muy difícil en la edad adulta ser violento. Es una conducta que es difícil de reproducir si no se ha vivido el modelo. Hay una transmisión intergeneracional del maltrato, mientras se está en la construcción de la personalidad y en la construcción del afecto (Amorós, 1995). Por ello, para tratar de erradicar la violencia se ha de cortar con el ciclo de la violencia y 


\section{San Segundo \& Codina-Canet-Violencia de Género}

con su trasmisión intergeneracional, y así evitar dar continuidad a esta transmisión. Los niños que crecen en un ambiente donde hay violencia son los denominados hijos de la violencia (Pérez del Campo, 1995), que la padecen, la aprenden y la perpetúan, en sus diferentes roles como víctima o como victimario.

La violencia se manifiesta de múltiples formas, en relaciones de abuso, de acoso, en los celos patológicos y enfermizos. Los celos son formas de control, de dominación y de abuso, no son amor y generosidad, sino control y cosificación del otro. La violencia también tiene su manifestación en el miedo aunque quien lo padezca trate de ocultarlo (Lorente, 1999). También en el aislamiento social, pues para dominar y someter a una persona es imprescindible aislarla de su entrono afectivo, primer paso que sigue el maltratador es el de ir destruyendo, poco a poco, todas las fuentes de apoyo externo --trabajo, amistades y familia-- que tiene la mujer, para dejarla aislada únicamente en la relación de pareja (Lorente, 2006). Sin contexto afectivo hay mayor vulnerabilidad frente a las agresiones. También en el control que se ejerce sobre los hechos de su vida cotidiana, por ejemplo en control de las llamadas a su móvil, en el control sobre su forma de vestirse, en sus costumbres o en cualquier otro aspecto sobre el que se ejerza control. También en la manipulación, manipular a otro es tratarle como un objeto de uso, es cosificarlo y en la anulación y faltas de respeto, donde se trata de descalificar de anular y también en la falta de respeto. La violencia persigue un fin último que es la destrucción del otro (Pérez del Campo 1995). Y son múltiples los métodos de humillación establecidos por el patriarcado, cuando mediante la violencia se persigue degradar la autoestima de la mujer.

La característica de un maltratador, fundamentalmente, es que no existe un perfil único, pero sí existe la forma de llevar a cabo la agresión. Persiguen dominar y someter, el objetivo del maltratador es siempre premeditado, utilizan la violencia en su propio beneficio y que, no son personas enfermas (Lorente, 2006), saben lo que hacen, carecen de resonancia afectiva, o sea no les duele el dolor de los demás. Esto se produce porque no construyeron, de forma adecuada, su personalidad afectiva. Son manipuladores, (este vocablo procede de la voz latina manus, o sea que se manipula aquello que se puede asir con las manos) en tanto que tratan a los demás como un objeto, los cosifican, son para ellos un objeto de su uso. El violento utiliza la violencia con el fin de doblegar la voluntad de la víctima. No es un enfermo mental, 
ya que éste no sabe lo que hace y por tanto es inimputable. Sin embargo el violentó sí sabe lo que hace. Actúa como el animal depredador, selecciona a la víctima y escoge el lugar del ataque, y cuando la presa se descuida le ataca. El depredador es un animal que vive a costa de otro, e incluso sus agresiones puedes ser objeto de clasificaciones como los pitbull y los cobra (Jacobson \& Gottman, 2001). El abusador tiene actitudes sexistas y creencias estereotipadas de las mujeres. Ve amenazado permanentemente su poder e impone el aislamiento social (Lorente, 2006). Tienen gran capacidad de persuasión de su conducta violenta, la justifican y minimizan. No asumen lo que hacen, no asumen el daño que causan a los demás. Utilizan todo tipo de estrategias como la culpa (Mizrahi, 2003) y la descalificación, con el ánimo de crear inseguridad y fomentar la dependencia. Hacen secuestro de sus víctimas en el propio hogar. Critican constantemente y afean la conducta en público y en privado de quien quieren someter con el ánimo de crear inseguridad y fomentar la dependencia.

El violento fuera de casa puede saber actuar y tener formas de conducta socialmente aceptadas como comportamiento educado, alegre, amable, seductor, solidario, atento e incluso respetuoso. Y puede saber representar una imagen social opuesta a la que tiene en el ámbito privado (Pérez del Campo 1995). A pesar de ser capaces, en numerosos casos, de crear una imagen adecuada de sí mismos, se trasluce su conducta violenta, se puede traslucir en detalles nimios, ya que socialmente se invisibiliza y minimiza la violencia contra las mujeres.

\section{Mujeres que Padecen Violencia de Género}

La mujer, en un primer momento de su relación con un violento puede estar confusa y desorientada (Lorente, 2003), haciendo renuncias a su propia identidad y atribuyendo al agresor aspectos positivos que la ayudan a negar la realidad. De ahí el título de la película dirigida por Icíar Bollain Te doy mis ojos, viene a significar que en al elación con un violento, se le plantea ahora voy a mirar a través de tus ojos no de los míos. La mujer inmersa en la relación violenta se encuentra aturdida y confundida por la falta de sentido que el agresor impone en su vida, sin poder comprender lo que sucede, sola y aislada de su entorno familiar y social y en constante tensión ante cualquier respuesta agresiva de su pareja (Varela, 2002). Marie-France 


\section{San Segundo \& Codina-Canet-Violencia de Género}

Hirigoyen habla de consecuencias a largo plazo refiriéndose a las etapas por las que pasan las víctimas a partir del momento en que se dan cuenta del tipo de relación en la que están inmersas. Durante la primera fase, las mujeres pasan un choque inicial en el que se sienten heridas, estafadas y avergonzadas, además de encontrarse apáticas, cansadas y sin interés por nada (Hirigoyen, 1999).

Las características de las personas que sufren relaciones de abuso no existen a priori, sin embargo cuando se padecen relaciones de dominación, de sometimiento y de violencia durante un tiempo largo se adquieren unas características como son baja autoestima, ansiedad, estrés, trastornos alimentarios. Es la propia víctima la que termina por cederle todo el terreno, sumida en la inseguridad provocada por ataques directos a la autoestima (Pérez del Campo, 1995). La dependencia también es un factor clave, los violentos, al no tener relaciones de afecto, establecen relaciones de dependencia y de codependencia y estimulan esta forma de relación (Norwood, 2006). En la mujer que ha sufrido violencia, se produce una adaptación a la situación aversiva caracterizada por el incremento de la habilidad de la persona para afrontar los estímulos adversos y minimizar e invisibilizar el dolor, además de presentar distorsiones cognitivas como la minimización, la negación o la disociación; debido al cambio en la forma de verse a sí mismas, a los demás y al mundo (Lorente Acosta 2003). La mujer se comporta como su entorno invisibiliza y minimiza la violencia. La violencia de género ha sobrevivido por una ocultación y minimización del problema, porque, en caso contrario, se hubieran tomado, mucho antes, medidas para acabar con ella (Lorente, 2006).

Todos estos efectos se equiparan al trastorno de estrés postraumático que tienen todos aquellos que han padecido violencia, ya sea de una guerra, violencia de género u otros tipos de violencia (Herman, 2004), y cuyos síntomas y características incluyen: sentimientos depresivos y de rabia, baja autoestima, culpa y rencor, problemas somáticos, desarreglos, relaciones y conductas adictivas y dificultades en sus relaciones personales, reexperimentación del suceso traumático, evitación de situaciones asociadas al maltrato y aumento de la activación. También las personas que han sufrido violencia pueden tener dificultades para dormir y tener pesadillas en las que revivan lo pasado. Pueden estar continuamente alerta, hipervigilantes, irritables y con problemas de concentración. Además, el alto nivel de 
ansiedad genera problemas de salud y alteraciones psicosomáticas, y pueden aparecer problemas depresivos importantes. El estrés postraumático tiene muy difícil cura y se puede tener de forma crónica o latente, por lo que hay que trabajar en terapias para cronificarlo y así evitar que esté latente (Herman, 2004).

Muchas personas viven atrapadas en relaciones afectivas de dependencia y codependencia, enfermizas, de las cuales no pueden, o no les dejan abandonar (Norwood, 2006). El miedo, la indefensión aprendida, las mantiene atadas a una forma de tortura pseudoamorosa, de consecuencias fatales para su salud mental y física convertida en costumbre. Es como si todo el sistema psicológico se adormeciera y comenzara a trabajar al servicio de la adicción, fortaleciéndola y evitando enfrentarla a su vida real. Lenta y silenciosamente, el amor deja de ser a ser generosidad y respeto (Pérez del Campo, 1995), y a pesar del letargo afectivo, de los malos tratos y de la constante humillación de tener que demandar afecto, la persona apegada a una relación disfuncional se niega la posibilidad de un amor libre y saludable; se estanca, se paraliza. Por lo que es fundamental la ayuda psicológica, jurídica, social y otras.

Es importante discernir en el tipo de relaciones afectivas que se establecen, y escoger, y poner fin a otras en las que el desamor empieza a hacer acto de presencia, cuando surgen las primeras señales de alarma, cuando se pasa de la admiración al dolor o cuando se añora una mayor libertad. Es importante poner de manifiesto la necesidad de comprender los principios psicológicos que pueden generar relaciones afectivas de subordinación y de dependencia (Pérez del Campo, 1995).

\section{Formas de Violencia de Género}

El maltrato se reproduce de múltiples formas y generalmente se producen todas a la vez (Álvarez, 2006). En una relación de violencia puede producirse maltrato verbal, mediante insultos, descalificaciones u otros; maltrato emocional, en el que no se tiene en consideración los sentimientos del otro; maltrato social, en el que se denigra, aísla y se descalifican; maltrato sexual, el cual es muy amplio su espectro y abarca tratar al otro como un objeto, cosificarle, acosarte, rechazarte y otras múltiples formas; y 


\section{San Segundo \& Codina-Canet-Violencia de Género}

el maltrato económico, que también puede ser de muchos tipos esta forma de abuso.

La violencia física es aquella que puede ser percibida objetivamente por otros, que más habitualmente deja más huellas externas. Se refiere a empujones, mordiscos, patadas, puñetazos, y otros causados con las manos o algún objeto o arma. Es la más visible, y por tanto facilita la toma de conciencia de la víctima, lo que ha supuesto que sea la más comúnmente reconocida social y jurídicamente, en detrimento de la visibilización de la violencia psicológica (Lorente, 2006).

La violencia psíquica aparece inevitablemente siempre que hay otro tipo de violencia. Supone amenazas, insultos, humillaciones, desprecio hacia la propia mujer, culpabilización, desvalorización de su trabajo, de sus opiniones, de sus iniciativas, de sus creencias, de su vida. Implica una manipulación en la que incluso la indiferencia o el silencio provocan en ella sentimientos de culpa e indefensión, incrementando el control y la dominación del agresor sobre la víctima, que es el objetivo último de la violencia de género (Lorente, 2003).

La violencia económica es en la que el agresor hace lo posible por controlar el acceso de la víctima al dinero, tanto por impedirla trabajar de forma remunerada, como por obligarla a entregarle sus ingresos, haciendo él uso exclusivo de los mismos, llegando en muchos casos a dejar el agresor su empleo y gastar el sueldo de la víctima de forma irresponsable, obligando a ésta a solicitar ayuda económica a familiares o servicios sociales, arrebatándole sus bienes como sueldo herencia u otros, y sometiendo a la mujer a un nivel económico muy inferior al que vive el violento.

También es habitual la violencia social, en la que el agresor afea la conducta de su pareja de forma pública y privada, degradando su autoridad por ejemplo delante de los hijos. La violencia social también incluye el limitar los contactos sociales y familiares de su pareja, aislándola de su entorno (Álvarez, 2006) y limitando así un apoyo social importantísimo en estos casos, manipulando para que traicione a su entorno afectivo.

La violencia sexual puede ser de muchos tipos. Se ejerce mediante presiones físicas o psíquicas que pretenden imponer una relación sexual no deseada mediante coacción, intimidación o indefensión (Lorente, 1999). También es maltrato sexual cosificar a las mujeres en las relaciones sexuales, mantener relaciones perversas, rechazo sexual y otras muchas 
formas. Toda la erotización de la violencia también se incluye en el maltrato sexual. Hasta no hace mucho, la legislación y el sistema judicial no consideraban este tipo de agresiones como tales, si se producían dentro del matrimonio.

\section{Ciclos de la Violencia de Género}

La violencia se reproduce de forma cíclica. Al principio se inicia con una agresión muy tenue, un pequeño insulto o bien un comportamiento raro, pero en seguida se produce el arrepentimiento y reconciliación. Después se vuelve a producir otra agresión muy tenue y así sucesivamente, hasta que cada vez se producen con más frecuencia e intensidad y pueden llegar hasta la muerte, al final del cono.

El ciclo de la violencia también se inicia con una primera fase de acumulación de la tensión, en la que la víctima percibe claramente cómo el agresor va volviéndose más susceptible, respondiendo con más agresividad y encontrando motivos de conflicto en cada situación (Álvarez, 2006). La segunda fase supone el estallido de la tensión, en la que la violencia finalmente explota, dando lugar a la agresión del tipo que fuere. En la tercera fase, denominada de arrepentimiento y luna de miel, el agresor pide disculpas a la víctima, trata de mostrar arrepentimiento, e incluso puede llegar a hacer regalos. Esta fase va reduciéndose con el tiempo, siendo cada vez más breve y llegando a desaparecer. Este ciclo, en el que al castigo (agresión) le sigue la expresión de arrepentimiento que mantiene la ilusión del cambio, y genera gran confusión, ello da continuidad a la relación, por parte de la mujer.

La representación del ciclo pretende explicar la situación en la que se da violencia física, ya que la violencia psicológica no aparece de manera puntual sino que destila durante toda la relación, aunque también se manifiesta en forma cíclica (Álvarez, 2006). Con la violencia física se manifiesta de forma continua el sometimiento y control de la pareja.

La forma en que se reproduce la violencia es cíclica, y, más específicamente en forma geométrica de cono, se reproduce cíclicamente y cada vez con mayor frecuencia. Si las agresiones se produjeran de forma continua y lineal se abandonaría rápidamente la relación de violencia. Sin 
embargo, las agresiones se producen de forma cíclica según el patrón: Tensión - estallido y agresión - arrepentimiento - luna de miel.

\section{Dificultades para la Salida de una Relación de Violencia}

Salir de una relación de violencia es extremadamente difícil, solo desde el desconocimiento no se comprende la extrema dificultad que supone salir de la violencia, del tipo que fuere (Osborne, 2001). Acerca de la dificultad que entraña el abandono de una relación de violencia de género se han sucedido distintas argumentaciones, las cuales componen cuatro grandes corrientes argumentativas para explicar las causas por las qué no se sale de la violencia.

Al inicio del siglo XX con las teorías de Freud, imperaba la idea del masoquismo, en la que a la mujer se la caracterizaba de masoquista. El concepto de masoquismo femenino aparece en Freud en El problema económico del masoquismo, en 1924, el cual tuvo una amplia repercusión en el medio psicoanalítico post-freudiano. En su teoría Freud designa una situación característica de la feminidad como la de un ser castrado, dando legitimidad a la subordinación de la mujer al hombre (Falcón, 1991).

En la década de los años 70, la cual vivió una explosión de secuestros políticos, se interpretaba como el Síndrome de Estocolmo, el cual se trata de una reacción psicológica en la que la víctima de un secuestro, violación o retenida contra su voluntad, vincula una complicidad afectiva o identificación con quien la ha secuestrado (Síndrome de Estocolmo).

En las décadas de los años 80 y 90 se interpretó como Indefensión aprendida. Existe cierto paralelismo con el comportamiento de una rata en un laberinto experimental, aquélla aprende el camino rápidamente para llegar a la comida, pero una vez aprendido si se le da, de forma aleatoria, comida o descarga eléctrica morirá de indefensión aprendida. $\mathrm{O}$ sea se aprende a comportarse de forma pasiva con una percepción subjetiva de incapacidad que no responde a las oportunidades reales de cambio, lo cual se ha relacionado con depresión ya que la persona se inhibe con pasividad (Escudero et al., 2005). Generalmente las mujeres afectadas por la violencia tienen pocas capacidades para ayudarse a sí mismas, consecuencia del desgaste psicológico que provoca la continua exposición a la violencia y al desprecio que se sufre, quedando desamparadas e incapaces de lograr sus 
metas vitales, con ausencia de motivación. Resultado de un proceso sistemático de violencia, la víctima cree que está indefensa y que no tiene control alguno sobre la situación (Varela, 2002).

Finalmente, en la actualidad, desde la Psiquiatría se denomina Manipulación coercitiva o también lavado de cerebro, persuasión coercitiva, reforma de pensamiento o programación de conducta. Esto es lo que hacen los violentos, tratar al otro como si fuera un objeto manipulable. La manipulación coercitiva puede tener también correlación con el concepto jurídico de influencia indebida. Se trata de un sistema coordinado de control coactivo, graduado, ya que por medio de engaños se logra manipular e influenciar hacia un comportamiento determinado (Escudero et al., 2005). Es una técnica de control mental más eficaz que el dolor, la tortura, las drogas, el uso de fuerza física o las amenazas, ya que puede producir cambios más profundos, como el de actitudes, en la personalidad de los sujetos expuestos a ella. Éste es un programa de modificación de conducta que emplea la influencia psicológica en forma coercitiva para producir el aprendizaje y la adopción de creencias, ideas, actitudes o comportamientos. La estrategia esencial que utilizan los operadores de estos programas es la de seleccionar y coordinar, de forma sistemática y gradual, diferentes tipos de influencia coercitiva, ansiedad y tácticas productoras de 'estrés' sobre periodos de tiempo continuo. La víctima es sometida a pequeñas actuaciones invisibles. Cada paso es lo suficientemente imperceptible como para no identificar la naturaleza coercitiva del proceso utilizado y de los cambios que se van experimentando. No se percibe el propósito de dominación latente tras el programa psicológico coercitivo. En la actualidad ésta es la coordenada interpretativa que identifica la grave dificultad que entraña salir de una situación de violencia (Escudero et al., 2005).

Dar término a una relación de violencia entraña grandes dificultades, y solo existe una vía para salir de la violencia: marcharse. Pero ha de hacerse con medidas de seguridad, con ayuda especializada tanto psicológica como jurídica y de otro tipo (Barea, 2004). Hay que evitar la casa de la familia y de los amigos, pues este es el momento de mayor peligrosidad, cuando la víctima corta con la violencia. Además, para superar la violencia es necesario iniciar un aprendizaje para no permanecer en las relaciones de abuso, un aprendizaje de la asertividad, de la autoestima. Frente a la 


\section{San Segundo \& Codina-Canet-Violencia de Género}

violencia hay salida, y es imprescindible salir de la violencia para tener una vida en la dignidad (Pérez del campo, 1995).

La denuncia de una situación de violencia de género es muy importante. El fundamento mismo del patriarcado y del sexismo es la violencia, cuya expresión más visible son las mujeres que sufren violencia. Es muy importante ejercer la denuncia en España la violencia de género es un delito desde el año 2004. Pero al denunciar los malos tratos a las mujeres, de cualquier tipo que fuere, también tienen lugar dos hechos que refuerzan la desigualdad entre los sexos. Por una parte se individualiza el problema por el modo en que se denuncia. En la medida en que se centra más, e incluso se cuestiona a la víctima, y menos al agresor, se produce la negación de los aspectos estructurales de la desigualdad social de las mujeres (Pérez del campo, 1995). Por otra parte, también se reproduce la concepción de la mujer como un ser pasivo y dependiente. Por lo que las denuncias son imprescindibles pero complementarias con otras actuaciones para erradicarla

La denuncia a los hombres que llevan el maltrato al límite no es suficiente, no se están tomando medidas adecuadas contra el patriarcado, cuyas bases estructurales quedan intactas, sino contra aquellos hombres que lo hacen evidente. No se rechaza que los hombres ejerzan violencia contra las mujeres - siendo de carácter económico y a través de la división sexual del trabajo, la violencia fundamental- sino que se busca evitar que sus formas más extremas sean visibles.

Con el reconocimiento primero de se empezó a visibilizar la violencia de género. Las relaciones familiares han salido del ámbito privado, tradicionalmente el trabajo doméstico, para posteriormente empezar a visibilizar que el hogar no es sólo un lugar de afecto y protección, sino también un sitio del que en ocasiones es necesario escapar. La denuncia de la violencia de género pone en evidencia que las relaciones familiares pueden llegar a ser dañinas, y que el amor no es el único vínculo entre sus miembros, la violencia, el odio y el rencor también pueden estar presentes (Izquierdo, 2007). 


\section{Prevención frente a la Violencia: la Educación}

Para erradicar la violencia de género esta ha de ser abordada de forma más integral. En este sentido, es imprescindible educar e investigar contra la violencia de género, siendo necesario articular muchas medidas, en el marco educativo, científico e investigador Es imprescindible promover la educación en igualdad, así como la adopción de medidas que posibiliten alcanzar la igualdad. Desde la educación se han de realizar acciones preventivas (Flecha, 2012). En todos los niveles educativos es necesaria la enseñanza sobre el significado y alcance de la igualdad entre niñas y niños; la inclusión de perspectiva de género en distintas asignaturas; inclusión de nuevos modelos comunitarios y participativos más igualitario (Martín Casanova \& Tellado, 2012); la inclusión en los planes de estudio de enseñanzas y materias específicas de igualdad entre mujeres y hombres; la creación de estudios de universitarios específicos, en el contexto de distintas especialidades científicas; la promoción del conocimiento científico con el principio de igualdad entre mujeres y hombres; la realización de estudios e investigaciones especializadas en la materia; y el fomento de la investigación científica en distintos campos científicos atendiendo a las diferencias entre mujeres y hombres, todo ello recogido en la Ley para la igualdad efectiva de mujeres y hombres (Ley Orgánica 3/2007).

También la investigación científica se ha de realizar con perspectiva de género, pues la ciencia está inmersa en una sociedad cuyas barreras continúan con la discriminación por sexo, con unas fronteras segregadoras, siempre artificiales y construidas, que conllevan la construcción de un orden de representación simbólico determinado. La ciencia es constitutiva de las bases principales sobre las que se asientan los valores sociales, por lo que debe tener mayor compromiso social y ser pionera en la construcción paritaria del conocimiento (San Segundo, 2008).

El compromiso y participación activa de las universidades es imprescindible en el camino hacia la igualdad. Como ejercicio de plena ciudadanía, la universidad debería ser uno de los principales baluartes en la educación de la juventud ante la violencia (San Segundo, 2008). Pero, de hecho, la invisibiliza con su omisión, así la juventud universitaria vivencia cierta apariencia de no desigualdad, dentro del marco universitario, y a partir de esta omisión generalizada, se establecen cimientos de futuras 


\section{San Segundo \& Codina-Canet-Violencia de Género}

agresiones, en los estratos que han tenido un nivel educativo más alto, (contrario de lo que se sugiere desde ciertos mas media, en los que se trata de situar la violencia de género solo en contextos culturales, educativos y económicos más desfavorecidos). Vivimos en una sociedad donde la violencia queda velada de múltiples formas, lo que también ayuda a su reproducción.

Las actitudes contra la igualdad y el neomachismo están muy posicionados en la sociedad actual que reproduce las estructuras sociales, mientras que el camino hacia la igualdad conlleva una denuncia de la desigualdad (Izquierdo, 2007). En la juventud existe esta contradicción de valores, lo que se pone de manifiesto en el incremento de la misma en esta franja de edades. Hay que educar en valores de igualdad, de derechos humanos y de ejercicio de ciudadanía. Los milenios de cultura masculina y de exclusión de la ciudadanía a las mujeres, que nos anteceden, inciden en numerosos aspectos; conformándose una sociedad de género, es decir, compuesta por dos sexos, y en la cual detenta la autoridad, en términos generales, uno de ellos. Esta situación también tiene su plasmación en el ámbito educativo, donde la mujer durante siglos ha tenido vetado el acceso a la educación, al alfabetismo, y a los derechos civiles, fundamentos estos constitutivos de la ciudadanía. Por consiguiente, educar y concienciar a los jóvenes contra la violencia de género se hace imprescindible. Es una tarea fundamental del sistema educativo (San Segundo, 2008).

Es en el siglo XX cuando la mujer ha conseguido las primeras conquistas hacia la igualdad, por primera vez en la historia hay igualdad de derechos civiles entre hombres y mujeres. En el siglo XX la mujer ha accedido al espacio público, a la educación, a la alfabetización, a la universidad, al voto, a la igualdad de derechos civiles, al espacio público, al empleo cualificado remunerado. Sin embargo, la igualdad real todavía está por llegar. La violencia de género es un vestigio de desigualdad, que debe ser erradicada (Barea, 2004).

\section{Conclusiones}

La violencia sexista, contra las mujeres, subyace como problema estructural inmerso en la transmisión patriarcal de todas las culturas. En la actualidad se invisibilizan muchos comportamientos violentos, y entre ellos la violencia 
contra las mujeres, con el objetivo de minimizar su importancia y socializarlos en la normalidad. Así se perciben ciertas formas de violencia con normalidad y con tolerancia social que impide la protección de las víctimas y la prevención de nuevas formas de violencia

La violencia de género no está generada por unos hombres apasionados o enfermos como se transmite en los medios de comunicación, o bien hombres desvalidos y traumatizados por haber sido maltratados, a su vez, en su propia infancia. Se trata de una violencia y agresión aprendida social y culturalmente para controlar a las mujeres y que emplea múltiples métodos de subordinación, que han sido reproducidos durante milenios por el patriarcado. Su meta, degradando la autoestima de la mujer, es dominar en muchos aspectos. La violencia se fundamenta en un sistema basado en la idea de que hay seres superiores que tienen derechos y poder sobre los otros seres que consideran inferiores.

La violencia sexista subyace como problema estructural en la sociedad actual y, como tal, ha de ser abordada, para una adecuada convivencia social. Los entornos interpretativos de ideas, tradiciones, discursos, lenguajes, actitudes mentales, símbolos, ritos, mitos y valores que constituyen el ordenamiento simbólico de las mujeres son aspectos donde este problema radica y que han de ser abordados. La participación activa de los poderes fácticos, de la sociedad, de los medios de comunicación y del sistema educativo en tratar la violencia contra las mujeres y a las propias mujeres en un nuevo marco interpretativo de igualdad es esencial. Trasmitir el legado cultural, los saberes tecnológicos y científicos con criterios de equidad es esencial para el progreso, para el ejercicio de los derechos humanos, para la convivencia en sociedades plurales y pacíficas, y para una vida colectiva en dignidad.

\section{Referencias}

Álvarez, A. (2006). Guía para mujeres maltratadas. Consejería para la igualdad y bienestar social. Junta de Andalucía. Recuperado de http://www.angelesalvarez.com//wp-content/photos/Guia-paramujeres-maltratadas.pdf

Amorós, C. (1990). Hacia una crítica de la razón patriarcal. Buenos Aires: Anthropos.

Amorós, C. (1995). 10 palabras clave sobre Mujer. Estella: Verbo divino. 
Benjamín, W. (2001). Para una crítica de la violencia y otros ensayos. Madrid: Taurus. Recuperado de https://rfdvcatedra.files.wordpress.com/2014/08/benjamin-walterpara-una-critica-de-la-violencia-y-otros-ensayos.pdf

Barea, C. (2004). Manual para mujeres maltratadas (que quieren dejar de serlo). Barcelona: Océano Ambar.

Bautista, E. (directora). (2004). 10 palabras clave sobre la violencia de género. Madrid: Verbo Divino.

Beavior, S. (2005). El segundo sexo. Madrid: Cátedra.

Belli, S. Bonet, J. Calsamiglia, A. and Sáenz, X., (2012]. Imaginarios sociales de la violencia política. Recuperado de http://es.wikibooks.org/wiki/Psicolog\%C3\%ADa_Pol\%C3\%ADtica:_ Imaginarios_sociales_de_la_violencia_pol\%C3\%ADtica

Bourdieu, P. (2000). La dominación masculina. Barcelona: Anagrama.

Martin Casanova, N. \& Tellado, I. (2012). Violencia de Género y Resolución Comunitaria de conflictos en los Centros Educativos. Géneros. Multidisciplinary Journal of Gender Studies. 1, 3, 300-319

Cobo, R. (2017). La prostitución en el corazón del capitalismo. Madrid: Catarata

Escudero, A., Polo, C., López Gironés, M. \& Aguilar, L. (2005). Persuasión coercitiva, modelo explicativo del mantenimiento de las mujeres en una situación de violencia de género: Las estrategias de la violencia. Revista de la Asociación Española de Neuropsiquiatría. XXV, 95, 85-117. Recuperado de http://www.revistaaen.es/index.php/aen/article/view/15934

Falcón, L. (1991). Violencia contra la mujer. Vindicación feminista: Madrid: Colo

Flecha, A. (2012). Educación y prevención de la Violencia de Género en menores. Géneros. Multidisciplinary Journal of Gender Studies. 1, 2, 188-211

Herman, J. (2004). Trauma y Recuperación. Cómo superar Las consecuencias de la violencia. Madrid: Espasa

Hirigoyen, M. F. (1999). El acoso moral. El maltrato psicológico en la vida cotidiana. Barcelona: Paidós. Recuperado de http://baseddp.mec.gub.uy/Documentos/Bibliodigi/E1\%20acoso\%20m 
oral. $\% 20$ el\%20maltrato\%20psicologico\%20en\%20la\%20vida\%20coti diana.pdf

Izquierdo, M.J. (2007). Estructura y acción en la violencia de género. En

Violencia deliberada: las raíces de la violencia patriarcal. (pp. 223-

234), Recuperado de

http://www.moviments.net/espaimarx/docs/aa486f25175cbdc3854151

288a645c19.pdf

Jacobson, N. \& Gottman, J. (2001). Hombres que agreden a sus mujeres.

Cómo poner fin a las relaciones abusivas. Barcelona: Paidos.

Lerner, G. (1986). La creación del patriarcado. Barcelona: Crítica.

Recuperado de http://www.antimilitaristas.org/spip.php?article5195

Ley Orgánica 3/2007 de 22 de marzo, para la igualdad efectiva de mujeres

y hombres. Recuperado de

https://www.boe.es/buscar/doc.php?id=BOE-A-2007-6115

Lorente, M. (1999). Agresión a la mujer: maltrato, violación y

acoso. Comares: Granada.

Lorente, M. (2003). Mi marido me pega lo normal. Barcelona: Editorial Crítica.

Lorente, M. (2006). El rompecabezas. Barcelona: Editorial Crítica.

Maquieira, V. ; Sánchez, C. comp. (1990). Violencia y sociedad patriarcal.

Madrid: Ed. Pablo Iglesias.

Martín Casares, A. (2006). Antropología del género. Madrid: Cátedra, Col.

Feminismos.

Miguel, A. (2015). Neoliberalismo sexual. Madrid: Cátedra.

Osborne, R. coord. (2001). La violencia contra las mujeres.

Realidad social y políticas públicas. UNED Ediciones: Madrid.

Pérez del Campo Noriega, A. M.(1995). Una cuestión incomprendida: el maltrato de la mujer. Madrid: Horas y Horas.

Norwood, R. (2006). Las mujeres que aman demasiado. Barcelona: Zeta Bolsillo.

Mizrahi, L. (2003). Las mujeres y la culpa. Buenos Aires: Nuevo hacer. Recuperado de http://pachami.com/LilianaMizrahi/MujeresyCulpa/LasMujeresylaCul pa.pdf 
47 San Segundo \& Codina-Canet-Violencia de Género

Posada, L. (2015). Las mujeres son cuerpo: reflexiones feministas. Investigaciones Feministas. Madrid: Universidad Complutense de Madrid.

Rojas Marcos, L. (1995). Las semillas de la violencia. Espasa Calpe: Madrid.

San Segundo, R. (2008). La segregación de las mujeres investigadoras en la ciencia. El Rapto de Europa: crítica de la cultura. 13, (pp.53-60).

Sau, V. (2001). Diccionario ideológico feminista. Barcelona: Icaria.

Varela, N. (2002). Íbamos a ser reinas. Mentiras y complicidades que sustentan la violencia contra las mujeres. Barcelona: Ediciones B.

Venegas, M. (2010). La maldición de ser niña. Estructuralismo, postestructuralismo y teoría de la práctica en género y sexualidad. Papers. $\quad 1, \quad 130-156$. Recuperado de http://www.raco.cat/index.php/Papers/article/download/183744/23647 8

Rosa San Segundo Instituto Universitario de Estudios de Género, Universidad Carlos III de Madrid, España.

Adelina Codina-Canet Universidad Carlos III de Madrid, España. Contact address: rosa.sansegundo@uc3m.es 